\title{
Mirídeos neotropicais, CCXXXVII: Descrição de quatro espécies novas do gênero Peritropoides Carvalho (Hemiptera)
}

José C. M. Carvalho (')

\begin{abstract}
Resumo
Descrições de quatro novas espécies de Petritropoides Carvalho (Hemiptera, Miridae, Cylapinae) do Brasil, área de Manaus, Estado do Amazonas: Peritropoides ariasi n. sp., Reserva Ducke; P. barensis n. sp., P. das Laranjeiras; P. duckei $n$. sp., Reserva Ducke; P. pennyi $n$. sp., P. das Laranjeiras. Incluídas ilustraçōes e uma chave para identificação das espécies do gênero.
\end{abstract}

A cortesia do colega Norman Penny, entomólogo do Instituto Nacional de Pesquisas da Amazônia, possibilitou-nos estudar uma coleção de mirídeos feita nos arredores de $\mathrm{Ma}$ naus, sobretudo na Reserva Ducke e na P. das Laranjeiras, que nos revelou uma série de espécies novas. Oportunamente, pretendemos apresentar uma lista de espécies e completar descrições de novas formas da região. Uma grande parte do lote foi coligida pelo colega Jorge Arias, com auxílio de armadilha luminosa. Os tipos e grande maioria do material foram devolvidos à coleção do INPA (Manaus).

As ilustrações no texto são de autoria de Paulo Roberto Nascimento e Luiz Antônio Alves Costa, sob a supervisão do autor.

Peritropoides Carvalho, 1955

Proc. U.S. Nat. Mus. 103(3337): 622.

O gênero Peritropoides Carvalho é pióximo de Peritropis Uhler, 1891, sendo, no entanto, facilmente distinguivel pela presença de um colar distinto, lados do pronoto arredondados, não carenados, calos não sensivelmente elevados, embólio muito estreito, vértice liso e superfície superior do corpo chagren.

Espécie tipo do gênero. Peritropoides annulatus Carva!ho, 1955 coligido em orquídeas proverientes da Colômbia.

\section{CHAVE PARA IDENTIFICAC̨ÃO DAS ESPÉCIES DE PERITROPOIDES}

1. Porção apical dos hemiélitros com uma faixa castanho-escura ou negra, transversal e alcançando o embólio de ambos os lados .................... 2

- Porção apical dos hemiélitros sem faixa transversal escura bem marcada ...... 3

2. Cúneo pálido, negro apenas na extremidade apical .......... barensis $\mathrm{n}$. $\mathrm{sp}$.

- Cúneo negro, pálido na extremidade apical ............... annulatus Carvalho

3. Embólio marmorizado de vermelho; faixa avermelhada do olho ao clípeo; ápice do segmento I da antena com anel avermeIhado .......... quadrinotatus Carvalho

- Espécies sem a coloração acima .....4 4

4. Pronoto com mancha negra na margem posterior em forma de W; escutelo negro, exceto porção apical .. pennyi n. sp

- Pronoto sem a mancha acima; escutelo quando negro com faixa longitudinal pálida ...................... 5

5. Escutelo negro com faixa longitudinal pálida; área dos calos negra .. ariasi n. sp.

- Escutelo pálido ou marmorizado de castanho; pronoto sem mancha negra sobre os calos .............. duckei n. sp.

\section{Peritropoides ariasi n. s.} (Fig. 1)

Caracterizada pela coloração do corpo. MACHO: comprimento $2,0 \mathrm{~mm}$, largura 0,8 $\mathrm{mm}$, Cabeça: comprimento $0,2 \mathrm{~mm}$, largura $0,4 \mathrm{~mm}$, vértice $0,24 \mathrm{~mm}$. Antena: segmento I, comprimento $0,1 \mathrm{~mm}, \mathrm{II}, 0,4 \mathrm{~mm}$; III e IV, mutilados. Pronoto: comprimento $0,3 \mathrm{~mm}$, largura na base $0,8 \mathrm{~mm}$. Cúneo: comprimento $0,36 \mathrm{~mm}$, largura na base $0,32 \mathrm{~mm}$ (holótipo).

(1) - Museu Nacional, Rio de Janeiro, e Conselho Nacional de Desenvolvimento Científico e Tecnológico (CNPq). 


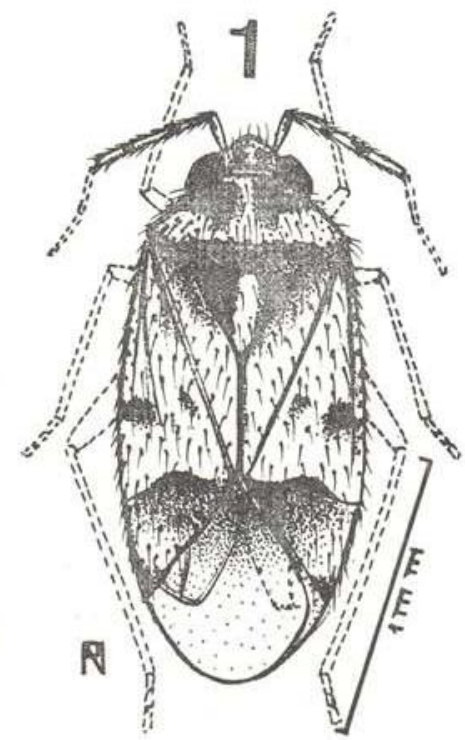

Fig. 1 - Peritropoides ariasi n.sp., macho, holótipo.

Coloração geral pardo-amarelada com manchas e pontuações castanhas; cabeça pálida, fronte e vértice com pontuações negras na base das cerdas, olhos castanhos, ápice do jugo com mancha castanha, gena e gula negros; antena com segmento I tendo mancha ou anel castanho, segmento II com dois anéis escuros.

Pronoto pálido-amarelado com área dos calos de coloração castanha, toda a superfície do disco salpicada com pontuações negras na base das cerdas; mesoescuto castariho com duas manchas pálidas (uma de cada lado da porção lateral), escutelo castanho com larga faixa mediana e extremidade apical pálidas.

Hemiélitro pálido-amarelado salpicado de pontuações escuras na base das cerdas, mancha castanha no terço apical do exocório e embólio e outra na extremidade marginal interna coalescente com outra na base interna do cúneo, este último pálido-amarelado, com mancha negra distinta no meio da margem interna e uma macula subapical avermelhada; membrana fusca.

Lado inferior e pernas pálido-amarelados, fêmures com dois anéis avermelhados na porção apicał, tíbias pálidas com 2-3 anéis negros; segmento I do rostro negro na parte basal e avermelhado na extremidade apical.
Pubescência do corpo cerdiforme, ereta ou semi-ereta, longa; rostro alcançando a extremidade distal do abdômen; pronoto trapeziforme, pouco afilado para a cabeça.

GENITáLIA - não ilustrada pelo fato de estar o exemplar fortemente colado em retângulo, como também dado o seu minúsculo porte. As características externas do holótipo são suficientes para o reconhecimento da espécie.

FÊMEA - semelhante ao macho em cor e dimensões.

HoLótipo - macho, Reserva Ducke, Manaus, Amazonas, BRASIL, 9.VIII.1977, Jorge Arias col., na coleção do Instituto Nacional de Pesquisas da Amazônia (INPA), Manaus. PARÁtipo - 1 fêmea, Brasil, Amazonas, P. das Laranjeiras, 8.14.VII.81, Jorge Arias col.

Difere das demais espécies do gênero pelas numerosas pontuações do corpo.

O nome específico é dado em homenagem ao colega Jorge Arias que coligiu numerosas espécies interessantes de mirídeos na área de Manaus.

\section{Peritropoides barensis $\mathrm{n} . \mathrm{sp}$.} (Fig. 2)

Caracterizada pela coloração do hemiélitro.

FÊMEA - comprimento 2,0 $\mathrm{mm}$, largura $0,9 \mathrm{~mm}$. Cabeça: comprimento $0,2 \mathrm{~mm}$, largura $0,4 \mathrm{~mm}$, vértice $0,20 \mathrm{~mm}$. Antena: segmento I, comprimento $0,1 \mathrm{~mm}$; II, $0,4 \mathrm{~mm}$; III, 0,1 $\mathrm{mm}$; IV, mutilado. Pronoto: comprimento 0,3 $\mathrm{mm}$, largura na base $0,8 \mathrm{~mm}$. Cúneo: comprimento $0,24 \mathrm{~mm}$, largura na base $0,28 \mathrm{~mm}$ (holótipo).

Coloraçãc geral castanho-escura e pálidoamarelada com áreas avermelhadas; cabeça branca na fronte e no vértice, com 4-5 pontos negros no primeiro e 6 ramificações negras no último, partindo do seu centro, clípeo branco com ápice negro, lados da cabeça com manchas pálidas e castanhas, olhos castanhos; antena com segmento I negro, pálido no ápice, segmento II pálido com 2 anéis negros, segmento III. negro. 


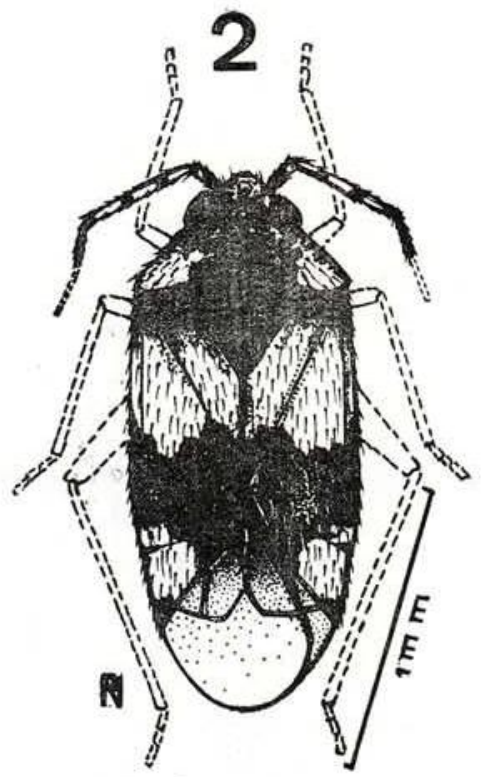

Fig. 2 - Peritropoides barensis n.sp., fêmea, holótipo.

Pronoto com colar negro tendo uma mancha branca no meio, calos salpicados de negro, disco com a porção mediana e posterior negra, área dos ângulos umerais pálida; mesoescuto e escutelo negros.

Hemiélitro pálido com porção basal e larga faixa mediana transversal cobrindo toda a área além do terço apical do clavo até o embólio, cúneo pálido, avermelhado no ápice e negro no ângulo basal interno; membrana fusca.

Lado inferior do corpo negro, pernas mutiladas.

Corpo comı pêlos semi-decumbentes pronoto e cabeça com pêlos cerdiformes disco afilado para a cabeça, rostro alcançando o ápice do abdômen.

мACHO - desconhecido.

HoLótipo - fêmea, Brasil, Amazonas, P. das Laranjeiras, 8-14.IX.81, Jorge Arias col., na coleção do Instituto Nacional de Pesquisas da Amazônia (INPA).

Difere das demais espécies do gênero pela coloração do corpo, notadamente da cabeça e dos hemiélitros.

"O nome específico é dado em alusão à tribo dos índios Barés que povoaram a região de Manaus na época do descobrimento.
Peritropoides duckei n. sp. (Fig. 3)

Caracterizada pela coloração do corpo.

MACHO - comprimento $3,0 \mathrm{~mm}$, largura $1,1 \mathrm{~mm}$. Cabeça: comprimento $0,2 \mathrm{~mm}$, largura $0,6 \mathrm{~mm}$, vértice $0,20 \mathrm{~mm}$. Antena: segmento I, comprimento $0,2 \mathrm{~mm}$; II, $0,6 \mathrm{~mm}$; III, 0,4 $\mathrm{mm}$; IV, 0,6 mm. Pronoto: comprimento 0,4 $\mathrm{mm}$, largura na base $0,8 \mathrm{~mm}$. Cúneo: comprimento $0,48 \mathrm{~mm}$, largura na base $0,28 \mathrm{~mm}$ (holótipo).

Coloração geral pálido-amarelada salpicada com manchas e pontos castanhos; cabeça pálida, fronte e vértice com manchas castanhas em toda a extensão, clípeo negro com mancha avermelhada na base, lados da cabeça salpicados de pálido e castanho, o!hos castanhos; antena com segmento I pálido tendo um anel castanho no meio, segmento II castanhoclaro, segmentos III e IV negros.

Pronoto pálido, salpicado de castanho, lados dos calos (que são claros) com uma mancha negra, colar pálido tendo duas manchas castanhas, disco posteriormente com duas manchas castanhas salpicadas de pontos

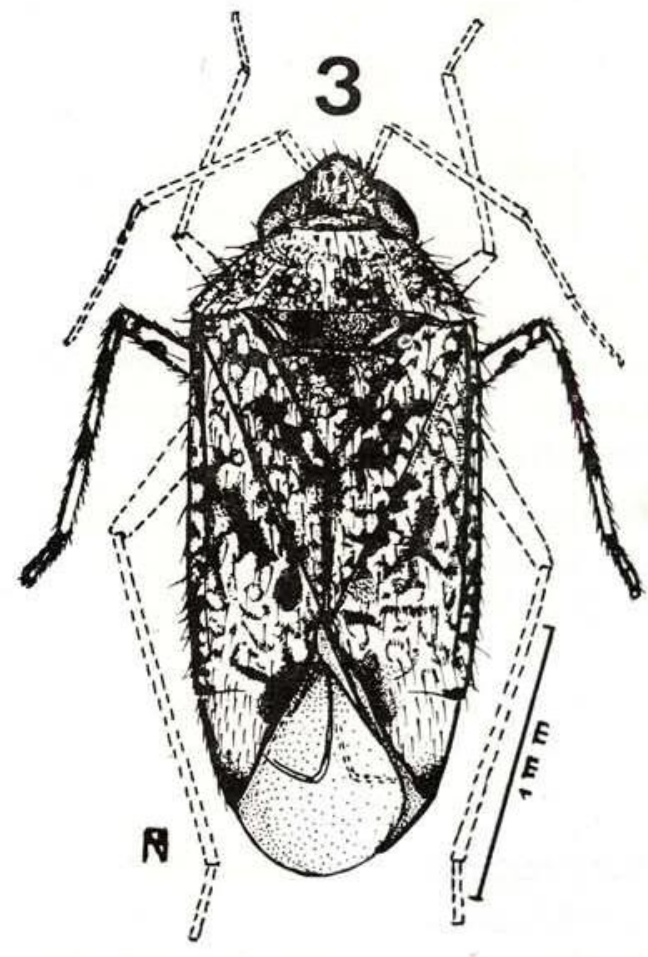

Fig. 3 - Peritropoides duckei n.sp., macho, holótipo. 
pálidos (separadas uma da outra por estreita linha pálida longitudinal), ângulos umerais pálidos; mesoescuto e escutelo castanhos, este último com ápice pálido.

Hemiélitro pálido, salpicado de castanho, região mediana do clavo e do endocório com manchas castanho escuras maiores, ápice do embólio e paracúneo castanhos, cúneo pálido, avermelhado na porção subapical; membrana translúcida.

Lado inferior castanho, peritrema ostiolar, coxas e metade dos fêmures I e II pálidos, fêmures posteriores negros na porção mediana, ápices de todos eles pálidos com dois anéis avermelhados, tíbias pálidas com 2-3 anéis castanhos, rostro pálido na metade basal.

Pubescência do corpo longa e ereta, semi-recumbente no pronoto; rostro alcançando a extremidade distal do abdômen; fêmures III fortes.

Genitália não dissecada por tratar-se de exemplar único, coligido em álcool. A ilustração de corpo inteiro servirá para identificar a espécie. Nesse grupo, os exemplares são de dimensões minúsculas.

FÊMEA - desconhecida.

HoLótripo - macho, Brasil, Amazonas, Reserva Ducke, AM-10 km 26, 16. VIII.1977, Jorge Arias col., na coleção do Instituto Nacional de Pesquisas da Amazônia (INPA), Manaus.

Difere das demais espécies do gênero pela coloração do corpo intensamente salpicada de manchas ou pontos castanho-escuros e pela coloração da antena.

O nome específico é dado em homenagem ao grande botânico da Amazônia, Adolpho Ducke, já falecido, meu dileto amigo.

\section{Peritropoides pennyi $\mathrm{n}$. $\mathrm{sp}$.}

(Figs. 4-7)

Caracterizada pela coloração do corpo e pela morfologia da genitália do macho.

MACHO - Comprimento $2,5 \mathrm{~mm}$, largura $1,1 \mathrm{~mm}$. Cabeça: comprimento $0,1 \mathrm{~mm}$, largu-

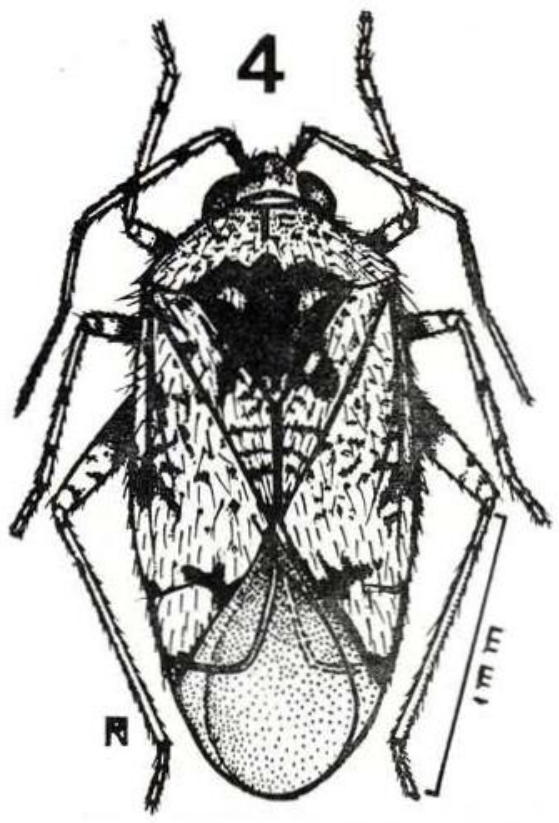

Fig. 4 - Peritropoides pennyi n.sp., macho, holótipo.

ra $0,9 \mathrm{~mm}$, vértice $0,28 \mathrm{~mm}$. Antena: Segmento I, comprimento $0,2 \mathrm{~mm}$; II, $0,6, \mathrm{~mm}$; III, 0,2 $\mathrm{mm}$; IV, $0,3 \mathrm{~mm}$. Pronoto: Comprimento 0,3 $\mathrm{mm}$, largura na base $1,0 \mathrm{~mm}$. Cúneo: Comprimento $0,36 \mathrm{~mm}$, largura na base $0,28 \mathrm{~mm}$ (holótipo).

Coloração geral pálido-amarelada ao citrino com manchas castanhas e avermelhadas; cabeça com a fronte cor de abóbora, vértice pálido com 2 manchas vermelhas de cada lado dos olhos, estes últimos castanhos, clípeo pálido, loro e búcula castanhos; antena com segmento I castanho, pálido no ápice, segmento II pálido com 2 anéis negros, segmento III mais claro, negro na base, segmento IV escuro.

Pronoto pálido-amarelado tendendo ao abóbora na área dos calos que é coberta por numerosos pontos escuros, margem posterior do disco com mancha castanha característica da espécie, em forma de $W$; mesoescuto negro com 2 manchas pálidas, escutelo castanho com ápice pálido.

Hemiélitros amarelados a citrinos, com manchas castanho escuras maiores: uma de cada lado do clavo; uma na parte mediana externa do cório e embólio; a terceira na parte mediana do ângulo distal interno do cório e área interna do cúneo, manchas castanhas a 
avermelhadas poderão ser vistas também no ápice do embólio e área subapical do cúneo; membrana translúcida.

Lado inferior castanho, ângulos posteriores da propleura e placa alar brancos, bases e ápices dos fêmures pálidos, os posteriores negros na metade basal e pálidos salpicados de vermelho, na porção apical, tíbias pálidas com dois anéis castanhos.

Corpo com pêlos rijos sob forma de cerdas no pronoto e pubescência semiereta no hemiélitro; rostro muito longo, alcançando a extremidade do abdômen.

GENITÁLIA - Penis (Fig. 5) como visto na ilustração, vésica com um espículo terminal, tubo seminal longo Parâmero esquerdo (Fig.

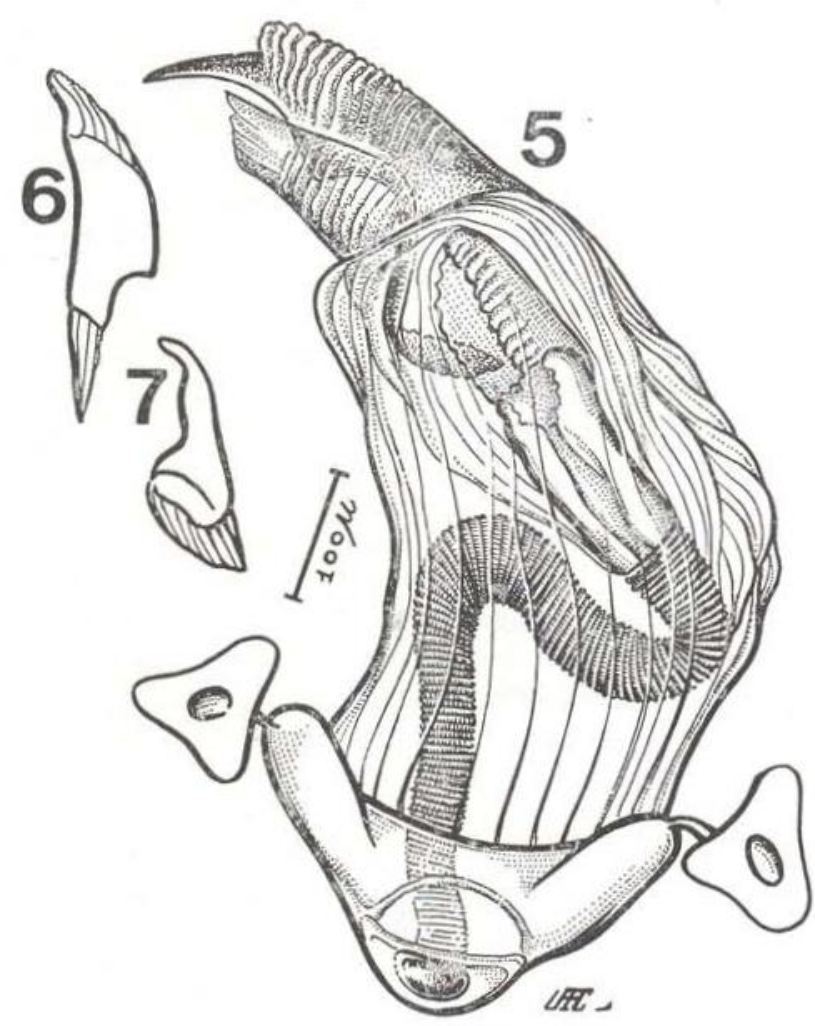

Peritropoides pennyi n.sp.: Fig. 5 - Penis; Fig. $6-$ Parâmero esquerdo; Fig. 7 - Parâmero direito.
6) simples, falciforme, com uma dobra subapical. Parâmero direito (Fig. 7) muito pequeno, alargado na base e afilado para o ápice.

FÊMEA - Desconhecida.

HoLótrpo - Macho, Brasil, Amazonas, P. das Laranjeiras, 4.IX.81, Jorge Arias col., na coleção do Instituto Nacional de Pesquisas da Amazônia (INPA), Manaus. PARÁtipos: 3 machos, mesmas indicações que o holótipo, nas coleções do INPA e do Museu Nacional, Rio de Janeiro.

Difere das demais espécies do gênero pela coloração do corpo e pela morfologia da genitália do macho.

O nome específico é dado em homenagem ao colega Norman Penny, atualmente encarregado da Coleção Entomológica do INPA e especialista em Neuroptera.

\section{SUMMARY}

This paper deals with the descriptions of four new species of Peritropoides Carvalho (Hemiptera, Miridae, Cylapinae) from Brazil, area of Manaus, State of Amazonas, as follows: Peritropoides ariasi n.sp., Reserva Ducke; P. barensis n.sp., P. das Laranjeiras; P. duckei n.sp., Reserva Ducke; P. pennyi n.sp., P. das Laranjeiras. A key for the species of the genus and illustrations are included.

\section{REFERENCIAS BIBLIOGRAFICAS}

CARVALHO, J.C.M.

1955 - Neotropical Miridae, LXIV: New bugs of the subfamily Cylapinae (Hemiptera). Proc. U.S. Nat. Mus., 103 (3337): 621.632, figs.

1957 - Catalogue of the Miridae of the World. Arq. Mus. Nac. R. Jan., 44, Par. I: 22.

(Aceito para publicação em 20/04/82) 